\title{
Ni inclusión, ni equidad. Otras miradas para la formulación de políticas educativas con justicia social ${ }^{1}$
}

\author{
Neither Inclusion nor Equity. Other Points of View for the \\ Formulation of Educational Policies with Social Justice
}

\author{
Nem inclusão, nem equidade. Outros olhares para a \\ formação de políticas educacionais com justiça social
}

\author{
Carolina Soler Martín² \\ María Cristina Martínez Pineda ${ }^{3}$ \\ Faustino Peña Rodríguez ${ }^{4}$
}

\section{Resumen}

El presente artículo, resultado de investigación, expone algunas de las discusiones y tensiones que fundamentan el fracaso de las políticas de equidad y de inclusión enmarcadas en el cumplimiento del derecho a la educación. La mirada crítica se realiza especialmente a las estrategias de focalización, compensación, masificación, eficiencia, entre otras políticas, que no modifican las estructuras sociales desigualadoras y, por el contrario, perpetúan e incrementan las brechas sociales; a la vez que desconocen las luchas por el reconocimiento de las diferencias humanas en sus dimensiones culturales, políticas y económicas. En este orden, podría decirse que los vínculos entre educación con y para la justicia social están por construirse.

El texto se estructura en dos apartados, el primero sitúa las problematizaciones vigentes en la política social y en las esferas culturales en relación con los procesos educativos; el segundo, presenta algunas iniciativas que buscan construir relaciones de proximidad entre educación y justicia social, desde la escuela, para avizorar elementos que contribuyan a configurar otros trazados de políticas sociales orientados a eliminar las injusticias sociales expresadas en exclusiones, desigualdades y discriminaciones por sexo, raza, color, género, condición social y económica, entre otras.

\section{Palabras clave}

justicia social; educación para la justicia social; políticas educativas; equidad; inclusión

\section{Abstract}

This paper, which is the result of a previous investigation, exposes some of the discussions and tensions that lay the foundation for policies of equity and inclusion in the context of the fulfillment of the right to education. A critical analysis is made of, in particular, the focalization, compensation, massification and efficiency strategies, among other policies, which do not modify the inequitable social structures and, conversely, perpetuate and increase the social gaps, while also being unaware of the struggles to recognize human differences in their cultural, political and economic dimensions. As such, it could be said that the links between education with and for social justice are about to be built.

The text is divided into two sections: The first one places current problematizations in social policy and in the cultural spheres related to educational processes; the second one presents some initiatives that seek to build close relations between education and social justice, from the school, to envision elements that contribute to shaping other social policy paths aimed at eliminating social injustices expressed in exclusions, inequalities and discrimination by sex, race, color, gender, and social and economic status, among others.

1 Este texto se fundamenta en los resultados de la investigación “Lineamientos pedagógicos para una educación con justicia social”, código DSI 397-15, adscrita al Centro de Investigaciones de la Universidad Pedagógica Nacional de Colombia.

2 Profesora investigadora de la Universidad Pedagógica Nacional de Colombia. Integrante del grupo de investigación Educación y Cultura Política. Doctora en Ciencias Sociales. csmartin@pedagogica.edu.co

3 Profesora investigadora de la Universidad Pedagógica Nacional de Colombia. Integrante del grupo de investigación Educación y Cultura Política. Doctora en Filosofía y Ciencias de la Educación. mmartinez@pedagogica.edu.co

4 Profesor investigador de la Universidad Pedagógica Nacional de Colombia. Integrante del grupo de investigación Equidad y Diversidad en Educación. Doctor en Educación. fprodriguez@pedagogica.edu.co 


\section{Keywords}

social justice; education for social justice; educational policies; equity; inclusion

\section{Resumo}

0 presente artigo, resultado de pesquisa, apresenta algumas das discussões e tensões que fundamentam o fracasso das políticas de equidade e inclusão em conformidade com o direito à educação. A crítica centra-se nas estratégias de focalização, compensação, massificação, eficiência, entre outras políticas, que não modificam as estruturas sociais desiguais e, pelo contrário, perpetuam e incrementam os fossos sociais, assim como desconhecem as lutas pelo reconhecimento das diferenças humanas em suas dimensões culturais, políticas e econômicas. Nesse sentido, é possível afirmar que os vínculos entre educação com e para a justiça social ainda estão por ser construídos.

0 texto está estruturado em duas partes: a primeira coloca as problematizações atuais na política social e nas esferas culturais em relação com os processos educacionais; a segunda, apresenta algumas iniciativas que procuram estabelecer relações de proximidade entre educação e justiça social, desde a escola, para esclarecer elementos que possam contribuir para a configuração de outras políticas sociais orientadas a eliminar as injustiças sociais representadas em exclusões, desigualdades e discriminações por sexo, raça, cor, gênero, condição social e econômica, entre outras.

\section{Palavras-chave}

justiça social; educação para a justiça social; políticas educacionais; equidade; inclusão

\section{Artículo recibido el 3 de marzo de 2017 y aprobado el 10 de enero de 2018}

\section{Introducción}

Con el interés de favorecer los vínculos entre educación y justicia social, a partir del enfoque crítico social, la producción de conocimiento surgido del proceso investigativo se orientó a reconocer las injusticias naturalizadas, estructurales y contingentes, concretadas en condiciones de desventaja, precariedad y vulnerabilidad que viven algunos sujetos educativos individuales y colectivos, para pensar y trazar iniciativas sociales y educativas tendientes a su eliminación y a la construcción de otras condiciones sociales.

Partimos de reconocer el fracaso de las políticas de equidad e inclusión, por un lado, porque su formulación se realiza de manera unilateral, sin participación directa de los sujetos de estas; las cuales obedecen a intereses externos, especialmente de organismos multilaterales que poco o nada conocen las realidades y necesidades socioculturales de los sujetos. Por otro, porque los resultados señalan que se incrementan cada vez más la exclusión, la discriminación y las desigualdades sociales de ciertos grupos poblacionales a quienes se les niega el derecho a vivir en condiciones dignas.

Desde las rutas exploradas con los sujetos de la investigación -maestros en formación y en ejercicio-, la lectura analítica de manuales de convivencia y el acercamiento a experiencias educativas que refieren patrones culturales dominantes, modelos democráticos precarios y lógicas empresariales en la educación, que impiden una educación social y humana, que contribuya a la eliminación de las injusticias y al reconocimiento de los sujetos desde su diversidad social y cultural como legítimos otros fue posible identificar núcleos de problematización y generar algunas iniciativas que fueron validadas con los educadores vinculados. Estos dos vectores de producción se recogen de manera sucinta en los siguientes apartados.

\section{Problematizaciones evidentes}

Durante los dos últimos decenios, los sistemas educativos de América Latina y de la mayoría de los países han sido orientados por lo que se conoce en el ámbito académico como el paradigma del pensamiento único ${ }^{5}$, calificado así porque sus defensores consideran que es la única alternativa para responder a las demandas de la educación, o más bien,

5 El paradigma del pensamiento único consiste en la redefinición de los modelos de desarrollo existentes frente a la necesidad de racionalizar la práctica gubernamental para afrontar el imperativo de la crisis fiscal y las políticas de ajuste, aspectos propios del posicionamiento mundial del proyecto neoliberal. 
para instalar y asegurar, desde el sistema educativo, sus preceptos de gobernabilidad macroeconómica.

La influencia de diversos organismos multilaterales (Organización para la Cooperación y el Desarrollo Económicos, OCDE; Fondo Monetario Internacional, FMI; Banco Mundial, $\mathrm{MB}$; Banco Interamericano de Desarrollo, BID; Organización Mundial del Comercio, omc) y de misiones internacionales, han intensificado la instalación de un modelo dominante que aunado a la dependencia de los recursos extranjeros y a la dramática situación de la deuda externa, han llevado a los países latinoamericanos a la creciente y sistemática pérdida de autonomía económica y de soberanía política, con todas las consecuencias en el campo social.

Quizá el hecho más sobresaliente es el reconocimiento de la reducción semántica que opera en las formaciones discursivas del neoliberalismo, que hace evidente cómo las reformas instalan una serie de lógicas y procedimientos de exclusión que ejercen un poder de coacción sobre otros discursos. Estos permiten y facilitan al sistema capitalista imponer su modelo económico en la organización de lo social y en la política educativa. Tales discursos operan a través de un conjunto de narrativas y prácticas codificadas como recetas, que son asumidas acríticamente y que actúan como referenciales de política; un sistema de ideas y creencias que han logrado materializarse en el ordenamiento social y educativo creando efectos perversos y adversos ${ }^{6}$. Estas "reformas padecidas por nuestras sociedades en las últimas décadas son, en realidad, crueles contrarreformas y acentuados procesos de involución social" (Borón, 2004, p. 19).

Para Cuenca (2012),

Tradicionalmente, la educación ha sido entendida como el vehículo por excelencia para lograr que los individuos de una sociedad puedan contar con igualdad de oportunidades. No obstante, para el caso de América Latina, la región más desigual del planeta, no existe una estructura

6 Para ampliar el análisis remitimos al capítulo 1 del libro Cartografía de las movilizaciones por la educación en Colombia 1998-2007 (Martínez, 2011). meritocrática fuerte y la "educación de calidad" está desigualmente distribuida, de modo que los factores sociales limitan o anulan los esfuerzos individuales de personas y grupos tradicionalmente excluidos. Por otro lado, la visión predominante y utilitarista de calidad educativa resulta poco efectiva para entender y atender las necesidades de poblaciones sumamente heterogéneas y desiguales. Por ello, las políticas educativas de hoy están ensayando diversas formas de lograr que el espacio educativo se transforme en un área más justa, pues justicia social y educación deben ir necesariamente de la mano en contextos sociales como el latinoamericano (p.80).

En este contexto, las reformas educativas parten de una noción de equidad que se sustenta en una posición igualitarista ${ }^{7}$ homogenizante de la sociedad y, por ende, de la educación, dejando de lado el análisis particular de las desigualdades y diferencias presentes en las dimensiones de la vida social de los sujetos. La mirada universalista de la igualdad, de acuerdo con D'Elia y Maingon (2004, p. 2) conlleva a una idea de equidad que borra diferencias entre sujetos, pues busca lo que es igualmente justo entre unos $y$ otros; lo cual dista de una perspectiva de equidad que se ajuste a las diferencias de unos y otros y que busque una igualdad en las diferencias. Para López (2005), esta última perspectiva de equidad

\section{[...] parte del reconocimiento de las desigualdades intrínsecas de los sujetos y engloba en sí mismo a todas las dimensiones de la igualdad en un planteo ineludiblemente ético [...]. No hay equidad sin igualdad, sin esa igualdad estructurante que define el horizonte de todas las acciones. (p. 68).}

Así pues, lograr equidad parte de la dificultad fundamental de contrarrestar los impedimentos que el poder social tradicional tiene instalados $y$ naturalizados. Por ejemplo, en escenarios de debate social y político, se ha internalizado el derecho a

7 "La capacidad integradora de esta visión igualitarista entra en crisis cuando las sociedades se van tornando cada más heterogéneas, y en las que la distribución de la riqueza es crecientemente injusta. Es precisamente la creciente desigualdad en el origen de las personas, en sus condiciones de vida, en sus trayectorias o en sus pertenencias culturales lo que pone en cuestión la pertinencia de una oferta educativa para todos" (López, 2005, p. 65). 
hablar o no desde algunos estilos discursivos versus la sobrevaloración de otros. Hay espacios sociales y lugares en los que se privilegia el discurso masculino considerándose que, aunque las mujeres hablen bien, tienden a brindar información y a formular preguntas más que a presentar opiniones o iniciar controversias; o bien, la gente blanca de clase media y mejor educada actúa como si tuviera el derecho a hablar y hacerlo con autoridad mientras otros se intimidan y tienden a no hablar o a pensar que sus intervenciones son vistas como desorganizadas ante los requisitos de la argumentación y la carga de formalidad o reglas del procedimiento (Young, 1997).

En relación con la inclusión, término altamente politizado y promulgado como respuesta y oposición a las exclusiones o marginaciones en cualquier ámbito social, puede entenderse, tomando las perspectivas sobre exclusión de Castells (1999), Jiménez (2008), entre otros, como el conjunto de procesos multidimensionales que pretenden contrarrestar los impedimentos sistemáticos en el acceso, disfrute o participación por parte de sujetos individuales o grupales en los bienes, derechos o posiciones sociales.

La inclusión toma múltiples formas y es experimentada por los sujetos de formas disímiles, según la esfera y niveles en donde se presentan las exclusiones, aunque, en términos generales, se dinamiza entre interacciones y determinaciones principalmente en ámbitos políticos, económicos y culturales (Subirats, 2004). Ahora bien, para Castel (2004) comprender la complejidad de las relaciones entre exclusión y la inclusión no puede caer en la simplicidad de describir la separación entre los que están adentro y afuera, pues lo más importante es establecer el lazo entre estas posiciones, reconstruir procesos, continuidades, rupturas o recorridos.

Las políticas y acciones de inclusión han seguido una línea tradicional de intervención en tanto, por una parte, han caído en el sesgo asistencialista, y por otra, en la trampa para la reflexión y la acción de atender las consecuencias y no las causas de la excusión. Castel (2004) afirma que el interés de las políticas de inserción ha eludido los esfuerzos hacia las causas o los procesos que desencadenan las exclusiones, pues resulta más fácil intervenir sobre los excluidos.

A continuación, de acuerdo con las perspectivas de equidad e inclusión, se presentan dos líneas de política que ponen en cuestión estas apuestas; una, las llamadas acciones focalizadas, $y$, otra, la discriminación positiva.

\section{Acciones focalizadas y compensatorias}

Las políticas educativas orientadas a la equidad y la inclusión se han centrado en acciones compensatorias que son excluyentes porque no abordan las causas de los problemas, más bien intentan remediarlos y sostenerlos; podríamos decir que en el caso de las políticas educativas, la premisa que las atraviesa es ofrecer educación pobre para pobres ${ }^{8}$. Tal tendencia atenúa aún más la exclusión escolar y la desigualdad social y económica, si se reconoce que la construcción de procesos sociales de inclusión, que permitan revertir las dinámicas de marginación y negación de derechos, dependen de decisiones políticas que busquen contrarrestar las causas de las desiguales y no solo algunas de ellas, que por lo general son las más visibles.

Esta primacía del concepto de focalización sobre el de universalización ha posibilitado que los gobiernos legitimen la exclusión, la inequidad y el incremento de las desigualdades sociales. $\mathrm{Al}$ asignar los recursos públicos de forma compensatoria $y$ focalizada para sectores poblacionales específicos (afrocolombianos, indígenas, personas sordas, con discapacidad, en situación de desplazamiento, entre otras), además de ampliar la esfera de desigualdades, se legitima la sectorización y segmentación de la política social, aceptando que el Estado incumpla su

8 “...] los pobres pueden tener acceso al sistema escolar, siempre que no se cuestione la existencia de redes educacionales estructuralmente diferenciadas y segmentadas, donde la calidad del derecho a la educación a la cual se accede está determinada por la cantidad de recursos que cada uno tiene para pagar por ella. En otras palabras, al ampliarse el acceso y la permanencia en un sistema educativo cuya estructura misma es segmentada, las posibilidades de ingreso y egreso del aparato escolar acaban siendo también inevitablemente diferenciadas. Que todos tengan acceso a la escuela no significa que todos tengan acceso al mismo tipo de escolarización. Esto siempre ha sido así en América Latina" (Gentili, s.f., pp. 6, 7). 
papel de organizador, ejecutor y garante del derecho a la educación para todos sin exclusiones.

Hasta aquí podríamos decir que se pone en cuestión el carácter público de las políticas sociales, porque al estar signadas por los principios de compensación y focalización se afirman las exclusiones y se generan más injusticias. Se cuestiona también lo público de las políticas públicas porque se planean y deciden a espaldas de los sujetos. La participación y representación de las hoy llamadas poblaciones vulnerables en la construcción y definición de las políticas es prácticamente nula o meramente enunciativa afirmando su exclusión. Los enfoques paternalistas y burocráticos cierran oportunidades para que aquellos que históricamente han sido marginados por su origen social y cultural, ejerzan sus derechos y sean reconocidos, por tanto, se les deja por fuera de contextos de cooperación social organizada (Young, 2000; Campillo, 2013).

El carácter remedial y débil de algunas políticas sociales y educativas ha generado, por ejemplo, la ampliación de cobertura escolar mediante el acceso masivo sin crear condiciones para la permanencia y para cumplir con las dimensiones de adaptabilidad y aceptabilidad del derecho a la educación, recordando que estas trascienden el acceso para exigir una educación pertinente y relevante de acuerdo con los sujetos, las diferencias entre estos y entre contextos.

En este sentido, no se disminuyen las brechas sociales ni la subvaloración a algunas culturas o formas de vida, pues nada cambia en la vida de los sujetos ni de las instituciones. Muchas veces se insertan sujetos a la escuela sin que medien procesos efectivos de inclusión que transformen las estructuras que excluyen, y además, se deja a la suerte y responsabilidad de los sujetos y de sus familias la compensación de los déficits producto de injusticias históricas.

En lo relativo a la ampliación de cobertura educativa, Colombia intensificó en las últimas décadas el número de estudiantes por grupo ${ }^{9}$ y generó

9 Con la llamada certificación de los entes territoriales, en 1998 se inicia un proceso de adecuación del sistema educativo, que le exigía al mismo, bajo el argumento de mayor gobernabilidad fiscal, una multiplicidad de contrarreformas que hoy se evalúan como catastróficas. Enunciamos algunas: masificación, se generó un alto grado de hacinamiento en los salones de clase en detrimento de la calidad (Decreto 3020 de 2002); mejora de la calidad, bandera de todos los gobiernos, esta se tradujo en el cumplimiento de estándares y competencias definidos de manera exógena por el Ministerio de Educación Nacional (MEN) desconociendo las necesidades territoriales, la diversidad y diferencias de los estudiantes (Decreto 1238 de 2009); mejoramiento de la eficiencia, representó para la práctica docente nuevas formas de control del tiempo y de las actividades del docente (Decreto 1850 de 2002); modificación del sistema de financiación de la educación que pasó a realizarse por capitación, es decir, se financia la demanda y no la oferta, con lo cual se debilitó significativamente tanto la calidad como la capacidad de mejoramiento del servicio educativo, sobre todo, en las instituciones oficiales.

La masificación de la educación ahonda el problema de la exclusión en cuanto afirma la meritocracia (Peña, 2013; Dubet, 2005). Al cambiar la lógica de la selección y del ingreso, las pequeñas desigualdades que en un inicio podrían no significar mucho y que se creerían diluidas en el interior del sistema educativo, terminan profundizándose y culpabilizando, no a la procedencia y las posiciones sociales, sino a los individuos en sí mismos por sus derrotas. Según Dubet (2005),

El mapa escolar registra las desigualdades sociales, y sus restricciones son más rígidas para las personas de sectores empobrecidos, encerrados en establecimientos ghettos donde la concentración de alumnos, con carencias económicas y marginaciones sociales y culturales, debilita aún más el nivel general y reduce las oportunidades

racionalizar el gasto público educativo recurriendo al aumento del número de estudiantes por profesor y elevar la eficiencia y la eficacia de la gestión. En suma, el enfoque del Estado como garante del derecho que se consignó en la Constitución Política y en las políticas de los años 90, se cambió por el del Estado como ente regulador que interviene en la evaluación y la medición de indicadores, pero abandona la responsabilidad en la prestación del servicio, con el supuesto de que el mercado garantizará la cobertura y la calidad (Rodríguez, 2002). 
de éxito, incluso las de los buenos alumnos. En cambio, las concentraciones de buenos alumnos en los establecimientos favorecidos refuerzan la calidad de la educación y el nivel medio de los alumnos (p. 28).

La realidad de nuestro sistema educativo es diferencial según la clase social y según la ubicación territorial y geográfica, es una verdad de apuño que los ricos estudian con los ricos y los pobres con los pobres, constituyéndose una segregación que está lejos de desaparecer y que se incrementa. Se suman a esta realidad, las críticas a la llamada calidad de la educación que es desigual en todos los casos y pone en escena la falacia de la llamada democracia participativa y los sueños de la equidad y la inclusión.

Podría decirse que, si bien los programas orientados a buscar la igualdad, la inclusión y la equidad llegan a sectores poblacionales previamente focalizados, esto ya es excluyente porque no se introducen garantías de permanencia y continuidad y porque las estructuras que los mantienen marginados no se transforman. Además, el camino de los programas deja rezagados -o complementa el rezago- de quienes enfrentan dificultades para vincularse al sistema y acceder a los derechos sociales y económicos.

\section{Discriminación positiva}

La discriminación positiva es un término que se ha instalado en la educación y en otros sectores también bajo la nominación de acciones afirmativas. Desde estas, se han caracterizado y focalizado poblaciones que ameritan una apertura exclusiva de cupos educativos o una atención especial por algunos méritos que son definidos por las élites o los productores de las políticas. Son acciones excluyentes porque generan una pretendida naturalización de las diferencias sociales atribuidas o innatas a un grupo específico, y porque son un modo de remediarlas sin erradicar de fondo los déficits. En el ámbito educativo, a causa de esta discriminación positiva, las desigualdades sociales entran directamente a la escuela y se reproducen en su seno en vez de tender a erradicarse ${ }^{10}$.

10 Citamos algunos ejemplos existentes en Colombia: el programa gubernamental Ser Pilo Paga, favorece a los estudiantes de estratos
Siguiendo las consideraciones de Dubet (2005), con la pretensión de lograr una mejoría en la igualdad de oportunidades, la discriminación positiva debería dirigirse a individuos concretos y no a colectivos; además, el tratamiento diferencial podría guiarse desde la singularidad de los estudiantes y no dejarlo en manos de un proceso que continúa afirmando las desigualdades sociales al interior de la escuela, en cuanto políticas remediales que no afectan aspectos estructurales de las situaciones de exclusión y desigualdad.

Igual crítica merece la meritocracia instaurada bajo la bina mérito/talento, en tanto gobierna las oportunidades sociales, no logra corregir injusticias ligadas al origen y condiciones iniciales de los individuos y grupos sociales, más bien las acrecienta. Como afirma Puyol (2010), la meritocracia no es un ideal igualitario.

Mientras que la igualdad resalta que todos somos iguales, la meritocracia consiste en encontrar el mejor. Su finalidad no es reducir las desigualdades sociales, es decir, el espacio que separa a los de arriba de los de abajo, sino encontrar un modo diferente de legitimarlas, un modo nuevo y moderno de acceder a la jerarquía social que sustituya el nacimiento por la capacidad. (pp. 14-15).

Hasta aquí se ha hecho visible la permanencia de las inequidades y exclusiones en el sistema educativo, en las instituciones y en los procesos pedagógicos; en todos se desarrollan prácticas de exclusión que no se problematizan y que se van naturalizando. Un ejemplo concreto en la escuela puede comprenderse en el estudio de Caicedo y Castillo (2012), el cual presenta cómo en los textos escolares la presencia de los afrocolombianos es desfigurada, sin definir la condición específica como se vive la negritud en nuestro país, las imágenes referentes a figuras afrocolombianas son escasas y, lo que es peor,

bajos con mejores resultados en la Prueba Saber 11 para ingresar a la educación superior; pero al hacerlo desde ese criterio deja de lado a otros que quizá tienen buen rendimiento académico, pero no lograron los estándares de la prueba. Otros programas similares son: créditos ACCES, fondos para poblaciones específicas, cupos especiales en instituciones educativas y sociales, porcentaje mínimo para mujeres en cargos directivos del Estado, entre otros. 
reproducen estereotipos, con lo cual se produce un gran cambio en la relación visibilidad/invisibilidad.

Con ejemplos como el anterior, así como otros que enfatizan en realidades sistemáticamente discriminantes, las instituciones y los sujetos individuales y colectivos han concebido el mundo con exclusiones, instalando las diferencias desde la desigualdad, asumiendo como naturales miradas que subvaloran, denigran, humillan a unos otros; además, sin preguntarse sobre opciones de participación para modificarlo.

Significa que las nociones de equidad e inclusión, tal como han sido instaladas y concebidas, se enfrentan a problemáticas y conceptualizaciones que exigen redefinirlas y pensarlas desde otras racionalidades. Mantenemos la apuesta porque se agencien políticas justas, desde acciones colectivas y desde estudios rigurosos que acompañen y orienten la construcción de iniciativas que busquen hacer asequibles los bienes de mérito ${ }^{11}$ para todos los sujetos sin distinciones.

\section{¿Es posible pensar otras políticas sociales y educativas? Vínculos entre educación y justicia social}

El tiempo de actuar es ahora, porque ya no aguantamos más la injusticia social en el mundo y porque hay un colapso ecológico. Sin embargo, por otro lado, hay un sentimiento opuesto, que es el sentimiento de que, dada la amplitud de los problemas que enfrentamos, necesitamos cambios muy complejos y muy amplios, que son cambios civilizacionales: necesitamos otra civilización. Ya no basta tomar el poder; hay que transformar el poder, hay que transformar las sociedades.

Santos (2003, p. 13).

11 Los bienes de mérito son "entendidos como aquellos que se merece la gente por el solo hecho de serlo, por tanto, su satisfacción no puede estar sujeta a la dinámica del crecimiento económico, ni depender de su contribución al mismo. Los bienes de mérito son universales y el Estado y la sociedad deben garantizar su provisión, puesto que quienes estén privados de ellos encuentran serias limitaciones para desarrollar sus capacidades. Estos bienes son convenidos socialmente y se expresan en el contrato social que por excelencia es la Carta Constitucional: libertad, justicia, seguridad, educación, salud, nutrición y vivienda" (Corredor, 2010, pp. 24-25)
¿Desde dónde y cómo construir esos nuevos trazados? Este apartado plantea algunas iniciativas y desafíos que articulan la educación con la justicia social.

Las luchas por hacer efectiva la educación como bien público y por construir justicia social han pugnado por deconstruir hegemonías y construir desde otros referentes las políticas sociales. Todo esto sin mayores resultados hasta la fecha. Caben aquí los planteamientos de Bourdieu cuando afirma que,

[...] la verdadera medicina, siempre según la tradición hipocrática, comienza con el conocimiento de las enfermedades invisibles, vale decir, de los hechos de los que el enfermo no habla, ya sea porque no tiene conciencia de ellos o porque olvida comunicarlos. Sucede lo mismo con una ciencia social preocupada por conocer y comprender las verdaderas causas del malestar que solo se expresa a la luz del día a través de signos sociales difíciles de interpretar por ser, en apariencia, demasiado evidentes. (p. 558).

Retomando el epígrafe y haciendo propia la metáfora de Bourdieu, se plantea la necesidad de pensar y actuar desde un nuevo paradigma emergente, entendiendo que los paradigmas socioculturales están en devenir permanente. Santos (2003) presenta una crítica inscrita en la tradición de la teoría crítica moderna, que según su criterio se expresa en tres puntos fundamentales: uno, no concibe estrategias emancipadoras en el ámbito del paradigma dominante porque estarían condenadas a convertirse en reguladoras a usanza del viejo estilo. Propone asumir el pensamiento crítico desde una posición paradigmática, esto es, no ir por el camino ni de la regulación ni de la emancipación, sino fundamentándose en una crítica radical al paradigma dominante; dos, en dirección al estatuto y objetivos de la crítica, señala que mientras la teoría crítica moderna se orienta a la desfamiliarización, el paradigma emergente debe velar por una familiaridad con la vida. Se desfamiliariza temporalmente mientras se crea una nueva familiaridad; finalmente, el nuevo paradigma critica y se autocritica permanentemente. 
De cara a la construcción de un nuevo paradigma, se hace necesario vincular los conceptos de justicia y justicia social, para lograr las reconceptualizaciones necesarias. Al respecto, diferentes pensadores e intelectuales buscan redibujar la teorización y práctica de la justicia, en discusión con autores clásicos como Rawls (1995), Bentham (1789), Nozick (1988), Stuart Mills. Direccionados desde otras perspectivas como la balanza y el mapa (Fraser, 2008), pasando de la igualdad de oportunidades a la igualdad de posiciones (Dubet, 2005), de la democracia deliberativa y del interés personal a la democracia comunicativa (Young, 1997); también, estableciendo debates y relaciones entre desarrollo de competencias y capacidades (Nussbaum, 2012). De este mapa de autores y conceptos se pueden derivar algunas aproximaciones para establecer relaciones entre justicia social y educación.

La justicia es uno de los principios y pilares para vivir en sociedad, para mantener el orden social, garantizar el cumplimiento de los derechos humanos y promover la convivencia en paz en medio de las diferencias. La justicia social, por su parte, tiene múltiples acepciones, para el caso que nos ocupa, se considera una herramienta analítica y de acción orientada a desactivar las limitaciones e injusticias económicas, culturales y políticas.

Las limitaciones relacionadas con la dimensión económica de la justicia social se expresan en injusticia distributiva derivada de la perversa distribución de recursos materiales y simbólicos, hecho que genera exclusión social por desigualdades económicas. Las limitaciones relacionadas con la dimensión cultural son injusticias de reconocimiento, las personas se ven impedidas para interactuar en condiciones de paridad porque no viven en escenarios que valoren pública y positivamente las diferencias y heterogeneidad de todo o cualquier orden. Las limitaciones políticas se refieren a injusticias de participación, se expresan en la ausencia de participación directa o de representación para la definición de políticas sociales o de cualquier decisión que afecta la propia vida (Fraser, 2008).
La justicia social, entonces, impulsa la construcción de posibilidades para acceder a condiciones de vida digna y satisfacer las necesidades humanas, entre otros propósitos. En suma, la justicia social puede comprenderse como la encargada de gestionar y provocar la eliminación de las desigualdades, inequidades y exclusiones sociales producidas; de un lado, por las brechas sociales que hoy existen entre la perversa clasificación entre ricos y pobres; de otro, por las construcciones culturales que propugnan por la homogeneidad y excluyen lo diferente en un mundo que es diverso y cambiante.

Aquí es necesario reconocer que las injusticias forman parte de esos redibujamientos necesarios en los sentidos que plantea Young (1997), para quien la injusticia estructural no es lo mismo que las injusticias provocadas por actos individuales o aquellas provocadas por una pluralidad de acciones de difícil definición. Hay procesos socioestructurales que contribuyen a la vulnerabilidad de los sujetos, cuando, por causa de ciertos grupos a los que se les puede denominar de poder, "son susceptibles de caer en determinadas vulnerabilidades por carecer de los medios necesarios y suficientes para poder desarrollar sus capacidades" (Young, 2011, p. 69). Si bien, a través de estos procesos no hay una intención de agencia por producir injusticias en sujetos o grupos específicos, en las acciones y políticas particulares (impuestos, educación de baja calidad, corrupción, violencias, movilidad social y física...) que tienden a afectar a los más desfavorecidos, se producen injusticias sociales históricas, económicas y políticas.

La idea de justicia de Young se ubica en un ámbito de tensión entre lo inmediato y lo estructural, en donde las exigencias de la inmediatez son una de las situaciones en las que se elude hacer justicia en lo estructural (Campillo, 2013), y entonces, en la vida cotidiana, la gente es expulsada de la participación en una vida digna, plena y activa en la sociedad, lo cual conlleva a marginaciones extremas que siguen instaladas en las estructuras.

En este sentido, podría afirmarse que a partir del reconocimiento de las diferencias y de las injusticias, la noción de equidad rompe con el determinismo 
del pasado y la homogenización, para centrarse en la búsqueda de una igualdad como horizonte de las políticas educativas. También, genera implicaciones de carácter ético y político ${ }^{12}$, dado que exige una toma de posición respecto a determinar cuál es el criterio de igualdad estructurante que debe ser considerado, y por otro lado, la equidad y la igualdad son principios estrechamente relacionados; la búsqueda de equidad implica la búsqueda de la igualdad, estos dos principios no se anulan mutuamente, ninguno es suficiente sin el otro.

Desde esta perspectiva, los criterios de equidad y de igualdad deben ser pensados como un proyecto abierto y cambiable (López, 2005) mediados por la justicia social. "Solo en estas condiciones la noción de equidad se pone en acción, resignificando el presente, ya no como determinación inevitable del pasado, sino como momento de construcción de ese futuro" (pp. 68-69). A partir de este vínculo, la equidad se convierte en requisito indispensable de la igualdad, pues esta tiene como función hacer frente a las injusticias y a las condiciones desfavorables de la población.

De igual manera, la equidad también hace frente al hecho de que las personas tienen diferencias en sus capacidades y condiciones sociales, culturales y económicas; tales diferencias no son producto del azar y de una ley natural (naturalización), sino que obedecen a desigualdades y jerarquías sociales que, de manera sistemática, crean tratos, posiciones, accesos, derechos y oportunidades diferenciales. Por lo que la exigencia de equidad debe traducirse, a su vez, en igualdad de oportunidades, en reconocimiento de facultades legales y sociales que permitan la garantía y el ejercicio pleno de todo aquello que forme parte de las capacidades humanas, que son actos de justicia social.

12 “La equidad tiene como base una toma de posición ética, moral y política ante desventajas que impiden una plena 'igualdad social', por consiguiente, enfrenta diferencias producto de relaciones de poder y categorizaciones sociales que rompen el vínculo social y que-sin razón valedera, por lo demás inadmisible desde el punto de vista humano y social- alejan a sectores de la población de contar con iguales derechos e iguales oportunidades de participar en la sociedad con la mejor calidad de vida posible" (D'Elia y Maingon, 2004, p. 10).
Por su parte, las políticas de inclusión y la educación inclusiva, ante la masificación escolar y el acceso de sujetos que décadas atrás no accedían a la escuela, y ante una reconfiguración de la equidad, estarían convocadas desde imperativos éticos y políticos, a considerar las diferencias de los estudiantes no para igualarlos desde perspectivas homogenizantes, no para cambiar a los sujetos, sino para ampliar y diversificar sus enfoques y prácticas en tanto la obligación de brindar respuestas y oportunidades a todos sus estudiantes. Además, estarían llamadas a focalizar acciones, no en grupos de estudiantes específicos, sino en los aspectos estructurales históricos que producen exclusiones, como sus normas, prácticas pedagógicas, relaciones, materiales didácticos, entre otros.

\section{Iniciativas a partir de la articulación entre educación y justicia social}

Contribuir desde la educación a la construcción de justicia social implica, entre otras acciones, la adopción del principio de paridad participativa propuesto por Fraser (2008), como regulador de acciones justas.

Este principio se asume como,

[...] una noción consecuencial, que especifica un principio sustantivo de justicia mediante el cual podemos evaluar los acuerdos sociales: estos son justos si, y solo si establecen que todos los actores sociales pertinentes pueden participar como pares en la vida social. Por otro lado, la paridad participativa es también una noción procesal, que especifica un procedimiento estándar mediante el cual podemos evaluar la legitimidad democrática de las normas: estas son legítimas si y solo si exigen el asentimiento de todos los implicados en los procesos de deliberación, equitativos y abiertos, en los que todos pueden participar como pares. En virtud de esta doble cualidad, la perspectiva de la justicia como paridad participativa posee el doble carácter reflexivo consustancial. Capaz de problematizar tanto la sustancia como el procedimiento, hace visible el mutuo enlazamiento de estos dos aspectos en los acuerdos sociales. Por ello, este enfoque puede hacer explícitas tanto las condiciones de fondo injustas que distorsionan la adopción 
de decisiones supuestamente democráticas como los procedimientos no democráticos que generan resultados sustancialmente no equitativos. (Fraser, 2008, p. 63).

Su adopción exige acciones como:

- Asumir que los referenciales de acciones justas se construyen mediante acuerdos entre las partes. Entender que los acuerdos son justos si y solo si se establece que todos los actores pueden participar como pares en la vida social. Aquí se presenta un desafío educativo: formar sujetos para participar en calidad de pares, autónomos, críticos y deliberativos, con capacidades para proponer y discernir.

- Entender el principio como una noción y acción procesal, que se aprende en la acción y mediante ejercicios regulativos concertados y construidos in situ. Es decir, que especifiquen rutas y procedimientos claros, hechos culturales mediados por normas y apuestas democráticas, justas y legítimas. Legítimas, en tanto hayan sido conocidas, aprobadas y apropiadas por los sujetos implicados a partir de procesos de deliberación, equitativos y abiertos, en los que todos pueden participar como pares. Esta construcción configura un segundo desafío educativo: construir las normas en contexto $\mathrm{y}$ a partir de procesos deliberativos.

- Reconocer y hacer explícitas las condiciones de injusticia que existen y que distorsionan la adopción de decisiones democráticas. La mejor forma de construir la justicia es partir del reconocimiento de las injusticias (Villoro, 2009). Este desafío conceptual y metodológico puede implementarse como práctica en las escuelas.

- Asumir la formación de sujetos de derecho. $\mathrm{Al}$ introducir este concepto, se busca aportar a la resignificación de las lógicas de elaboración de políticas, para que el punto de partida no sea la existencia de personas con necesidades que deben ser asistidas, sino la configuración y el reconocimiento de sujetos con derechos.
Estos establecen obligaciones correlativas y estas requieren mecanismos de exigibilidad y responsabilidad (Abravomich, 2004).

- La diferencia es el sello de nuestra singularidad. Todas las personas somos diferentes, no existe ningún ser humano igual a otro, cada quien posee singularidades y particulares por muchas razones: de orden genético, cultural y social. Es necesario enseñar a reconocer y a vivir con las diferencias, estas son connaturales y enriquecen las sociedades y las culturas.

Una segunda acción es la resignificación de las llamadas acciones afirmativas que, como ya se explicó, no contribuyen a disminuir o eliminar la marginación, discriminación, desigualdad y vulnerabilidad social y cultural.

Para ir más allá de las acciones afirmativas, es necesario que los saberes y prácticas ligadas a las etnias, mujeres, campesinos, jóvenes, ancianos, personas con discapacidad, nuevos grupos políticos, entre otros, conduzcan a comprender e instalar la diferencia como recurso democrático, tal como lo señala Hanna Arendt (1997). También, reconocer y asumir como natural las diferencias en su complejidad e integralidad, esto es, como un proceso que no se reduce al reconocimiento del otro, en conjunto, se dirige a la existencia de gamas de comportamiento, costumbres y valores que son comprendidas y respetadas en procesos interculturales sin que estas precisen ser rotuladas por grupos hegemónicos (Walsh, 2005).

Como se ha reiterado, ni inclusión ni equidad han servido para disminuir desigualdades. Una alternativa para que haya justicia social exige que el país instaure sistemas institucionales éticos, transparentes, sin corrupción; órganos de control eficientes, con capacidad para reconocer y promover la diversidad y las diferencias, sin miradas excluyentes. Políticas públicas que tengan un carácter potenciador que, por un lado, proporcionen las condiciones básicas y fundamentales para que las personas cultiven sus capacidades y, por el otro, cuenten con mecanismos que aseguren su sostenibilidad. Los gobiernos y el Estado en general están 
llamados a trazar políticas públicas en los que prime el principio de paridad participativa, que promuevan el desarrollo de capacidades y sean benéficas para la sociedad en general (Nussbaum, 2012). Capacidades que no estén basadas en la dupla costo/ beneficio, sino que se sustenten y complementen en la formación de sujetos de derechos, que vayan más allá del saber-hacer, en el sentido de desarrollar competencias.

Las políticas educativas que trabajen por la justicia social se caracterizan por su capacidad de modificar estructuras y afectar aspectos fundamentales como la estratificación social, formas jurídicas, normas institucionales, control social, tradiciones, valores, rituales y funciones a través de procesos de largo aliento que posibiliten eliminar injusticias (Soler y Peña, 2016). Estos son algunos de los desafíos y apuestas para la construcción de un paradigma emergente que asuma como principio la construcción de educación y paz con justicia social.

\section{Referencias}

Abramovich, V. (2004). Una aproximación al enfoque de derechos en las estrategias y políticas de desarrollo de América latina. Santiago de Chile: Centro de Estudios Legales y Sociales.

Arendt, H. (1997). ¿Qué es la política? Trad. Rosa Sala Carbó. Barcelona: Paidós.

Bentham, J. (1789). The Principles of Moral and Legislation. Cambridge, MA: Oxford University Press.

Borón, A. (2004). Estado, capitalismo y democracia en América Latina. Buenos Aires: Clacso.

Bourdieu, P. (1999). Capital cultural, escuela y espacio social. México D.F.: Siglo xxi Editores.

Caicedo, J. y Castillo, E. (2012). Yo no me llamo negrito... Racismo, primera infancia y educación en Bogotá. Ponencia presentada en la Conmemoración Día Mundial contra el Racismo "Por una educación libre de discriminación: del reconocimiento formal a la garantía real". Bogotá: Biblioteca Virgilio Barco.

Campillo, N. (2013). El significado de la crítica y de la responsabilidad política en Iris Marión Young. Enrahonar, 51, 41-59.
Castel, R. (2004). Encuadre de la exclusión. En S. Karsz, La exclusión: bordeando sus fronteras (pp. 55-86). Barcelona: Gedisa.

Castells, M. (1999). La era de la información. México: Siglo XXI Editores.

Corredor, C. (2010). Pobreza, equidad y eficiencia social. Bogotá: PNUD-MPS.

Cuenca, R. (2012). Sobre justicia social y su relación con la educación en tiempos de desigualdad. Revista Internacional de Educación para la Justicia Social, 1(1), 79-93. Madrid: Cambio Educativo para la Justicia Social, Universidad Autónoma de Madrid.

D’Elia, Y. y Maingón, T. (2004). La equidad en el desarrollo humano: estudio conceptual desde el enfoque de igualdad y diversidad. Venezuela: Programa de las Naciones Unidas para el Desarrollo.

Dubet, F. (2005). La escuela de las oportunidades ¿Qué es una escuela justa? Barcelona: Gedisa.

Fraser, N. (2008). Escalas de justicia. Barcelona: Herder Editorial.

Gentili, P. (s.f.). La exclusión y la escuela: el apartheid educativo como política de ocultamiento. Recuperado de: http://www.inau.gub.uy/biblioteca/gentili.pdf

Jiménez, M. (2008). Aproximación teórica de la exclusión social: complejidad e imprecisión del término. Rev. Estudios Pedagógicos, XXXIV(1), 173-186.

López, N. (2005). Equidad educativa y desigualdad social. Desafíos a la educación en el nuevo escenario latinoamericano. Buenos Aires: IIPE-Unesco.

Martínez, M. (2011). Cartografía de las movilizaciones por la educación. Bogotá: Universidad Pedagógica Nacional-Editorial Magisterio.

Ministerio de Educación Nacional. Decreto 3020 de 2002. Bogotá.

Ministerio de Educación Nacional. Decreto 1850 de 2002. Bogotá.

Nozick, R. (1988). Anarquía, Estado y Utopía. México D.F: Fondo de Cultura Económica.

Nussbaum, M. (2012). Crear capacidades: propuesta para el desarrollo humano. Barcelona: Paidós.

Peña, F. (2013). Distribución social del capital escolar en Colombia. Perspectiva socioeducativa. Bogotá: Alejandría Libros.

Puyol, A. (2010). El sueño de la igualdad de oportunidades. Crítica de la ideología meritocrática. Barcelona: Gedisa. 
Rawls, J. (1995). Teoría de la justicia. México D.F.: Fondo de Cultura Económica.

Rodríguez, A. (2002). La educación después de la Constitución. De la reforma a la contrarreforma. Bogotá: Magisterio.

Santos de Sousa, B. (2003). Crítica de la razón indolente. Contra el desperdicio de la experiencia. V. 1. Bilbao: Editorial Desclée de Brouwer.

Soler, C. y Peña, F. (2016). Factores político-estructurales, familiares e institucionales que inciden en el acceso $y$ permanencia en la UPN. (En prensa). Bogotá: UPN.

Subirats, J. (2004). Pobreza y exclusión social. Un análisis de la realidad española y europea. Barcelona: Fundación La Caixa.
Villoro, L. (2009). Los retos de la sociedad por venir. México D.F.: Fondo de Cultura Económica.

Young, I. (1997) La democracia y "el otro": más allá de la democracia deliberativa. Traducción de Mooney. Revista Jurídica, 5, 41-55. Recuperado de http:// www.palermo.edu/derecho/publicaciones/pdfs/ revista_juridica/n5N1-2000/051Juridica03.pdf

Young, I. (2000). La justicia y la política de la diferencia. Madrid: Cátedra-Instituto de la Mujer-Puv.

Young, I. (2011). Responsabilidad por la justicia. Madrid: Morata.

Walsh, C. (2005). Interculturalidad, conocimiento y decolonialidad. Signo y Pensamiento, XxIV(46), 39-50.

Para citar este artículo

Soler Martín, C., Martínez Pineda, M. y Peña Rodríguez, F. (2018). Ni

inclusión, ni equidad. Otras miradas para la formulación de políticas educativas con justicia social. Folios, 48, 27-38. 